\title{
TOWARDS A TRUSTED E-ELECTION IN KUWAIT : REQUIREMENTS AND PRINCIPLES
}

\author{
Asaad Alzayed $^{1}$, Ray Dawson ${ }^{2}$ and Abdulaziz Alkandari ${ }^{3}$ \\ ${ }^{1}$ Public Authority of Applied Education, Business College, Information Systems \\ Department, Kuwait \\ ${ }^{2}$ Department of Computer Science, Loughborough University, Loughborough \\ LE113TU,United Kingdom \\ ${ }^{3}$ Public Authority of Applied Education, Business College, Information Systems \\ Department,Kuwait
}

\begin{abstract}
Kuwait is a democratic country that has used paper ballots for its parliament elections for many years. Although many people are content with the paper ballot, a survey shows that it has drawbacks, which have made some people lose confidence in the system and would prefer a replacement electronic system. However, the survey also shows that voters are cautious about electronic voting and are not ready for a full internet-enabled system. The aim of this paper is to propose a step-by-step approach for introducing electronic voting system and to define a set of requirements that an e-voting system, which is planned to be used instead of paper-based voting system in Kuwait, should satisfy.
\end{abstract}

\section{Keywords}

[

E-voting requirements, Internet voting, Kuwait election

\section{INTRODUCTION}

Kuwait has the most democratic political system among the Arabic countries in the Arabian Gulf and its parliament is one of the most sustained democratic experiments in the Arab world [4].

Elections in Kuwait are held for the National Assembly for the interval of four years. The country is divided into five blocks or districts, and within each district each citizen (eligible voter) is able to vote for four candidates and the ten with the most votes in each district will be awarded a parliament seat.

Although, Kuwait society is small, approximately 1.3 million citizens, it is deeply divided into many factions such as Liberals, Islamists (Sunni and Shi'at), wealthier families, and tribal families, especially in the outlying districts. Although formal political parties are illegal in Kuwait, each of these factionscan strongly affect the voting system as voters rarely choose candidates who do not belong to their group [1]. This leads to hard fought campaigns that seem to revolve around neighborhood issues, pitting families and tribes against each other. Allegation of vote buying is widespread [11], and tribes and factions frequently (against the law) hold primaries

DOI : $10.5121 /$ ijmit.2014.6303 
in order to ensure that their members will focus their votes on a select few candidates.

While the voting system in Kuwait has helped establish a lead in democracy amongst the nations of the area, the system is clearly far from perfect. This motivated this research to examine electronic voting systems in the hope that election campaigns would connect more directly with the voter, deterring any corrupt practices and enabling campaigns based on ideologies rather than family and tribes loyalties.

The Kuwaiti government for many years has been using the manual, paper voting system. Although there are some problems with it, voters have generally accepted the system and have confidence in it. Therefore, if this system is going to be replaced with an electronic voting system, the new e-voting system should perform at least as efficiently and effectively as the old system. Failures in any type in the new voting system will jeopardize democracy and trust in the system.

The literature shows [13,15] some countries have cancelled their e-voting system before implementation because people didn't trust the system. This indicates that not all e-voting projects have succeeded in delivering a good result. For example, mistrust towards the Irish voting machine culminated in the cancelation of the respective project shortly before going live and, for the same reason, Germany and the Netherlands have persistently banned their voting machine from use at political elections [13]. Britain has also halted its trials of e-voting, because of problems with viruses and breaches of ballot security. Estonia is currently the only nation using E-voting successfully for national elections [19].

In this paper, we propose an e-voting system for Kuwait which involves electronic voting at a polling station, rather than through the Internet, to ensure that trust in the system can be maintained and still resolve most of problems of the old paper base voting system currently used in Kuwait.

\section{The current voting procedure in Kuwait}

This section briefly describes the paper-voting system in the state of Kuwait, which is similar to that of most democracies.

Citizens are only eligible to vote within their own district, each district will have one or more polling station depending on the size and number of towns and cities it covers. One of these polling stations will be the main station for consolidating all votes from other secondary polling stations in order to tally and count all the votes in the district.

Authorities have to register eligible voters before the election day. When the election day is determined and announced by the Kuwaiti government then, on that day, citizens can only vote at the polling station where their name is registered, and cannot go to any other polling station to vote for their candidates. On arrival, they must first show their identification card (digital ID card) to the polling official to enter the polling station, then they should go directly to the adjudicator to verify their name, district and their eligibility to vote. After all personal information and their eligibility to vote are verified and accepted by the adjudicator, the voter has to sign the record list to indicate that he or she has attended the election station. The voter is then given a paper ballot with all the candidates name listed for that district only. The voter then has to go to the polling-booth alone to cast their vote securely where nobody can see or coerce him or her. The paper ballot is then inserted in a glass ballot-box in front of the adjudicator. The anonymity is achieved by using the polling booth and the glass ballot box. 
At the end of the voting period, the election officials for each polling station within the same district will take the voting ballot-boxes to the main polling station for counting all votes for that district. The counting of the votes is run by government officials and judges. Vote collecting, counting and tabulating are done in front of observers (candidates representatives) and is broadcasted on television and radio stations simultaneously so that all citizens can watch the result live.

A paper ballot is considered cancelled if a voter chooses more than four candidates or writes their name or puts any suspicious mark on the ballot paper.

\section{A Survey to Determine Attitudes Towards E-Voting in Kuwait}

A survey was carried out to investigate the voter trust and satisfaction with the paper-based voting system that have been used in Kuwait for many years and the willingness to change this system to an electronic voting system. The survey also aimed to help assess and identify the features of the e-voting system that are needed for the acceptance of the system, for example, whether adding a paper trail or vote confirmation would be required. The survey also examined attitudes towards voting at a polling station compared to voting at home via the internet (Ivoting).

The survey was distributed using a hard copy paper to participant in two categories:

1- Young educated adults (age 21 or more) who can represent the current and future election process in Kuwait and who are mostly familiar with using the internet. These participant were chosen randomly from young employees who work in government ministries and the private sector. For each ministry and company visited, the department's manager was asked if he could give a permission for the survey representative to distribute the survey to his employees at the end of the working day. If they agreed, the survey was given to the employees who were willing to take part. The survey was collected immediately after it was completed.

2- Older, generally less educated people who have used the paper-based system before and rarely use the internet. These participant were chosen from the Kuwaiti families that agreed to participate in the survey. The survey representative visited the houses randomly (in a randomly chosen cities) to ask if they would like to participate in conducting a survey. If they agreed, then the representative gave them survey papers for each of the older adults living in the house. The survey representative either waited for it to be completed or it was collected later.

Approximately 200 people were sampled from the Kuwaiti eligible voters of which 130 responded, this represents a $65 \%$ response rate.

The survey consisted of closed and open-ended questions. The survey was divided into four sections: personal information of the participant, including their use of the internet, their satisfaction with the current voting system and their preferred voting methods, their reasons for preferring electronic voting at a polling station, and additional voting system features they thought would be desirable. All questions were asked in Arabic, but are translated into English for this paper.

The information gathered from the survey was analyzed qualitatively and quantitatively. The results are given in the next sections. 


\section{Demography and internet knowledge of respondents}

Table 1 shows that the majority of participants (70\%) were young adults aged 21 - 40 years old, the reason most of the participant were selected from this age category, was because these people are most likely to use the internet and may already have an understanding about the e-voting concept.

Table 1- Age of respondents

\begin{tabular}{|l|l|l|l|l|l|l|}
\hline Age & $21-30$ & $31-40$ & $41-60$ & $61-65$ & +65 & Total \\
\hline Frequency & 53 & 41 & 39 & 3 & 1 & 137 \\
\hline Percent & 38.7 & 29.9 & 28.5 & 2.2 & 0.7 & 100 \\
\hline
\end{tabular}

Table 2- Education Level of respondents

\begin{tabular}{|c|c|c|c|c|c|c|}
\hline & High & Diploma & Bachelor & Post & Others & Total \\
& School & & & graduate & & \\
\hline Frequency & 9 & 21 & 78 & 26 & 2 & 136 \\
\hline Percent & 6.6 & 15.3 & 56.9 & 19.0 & 1.5 & 100 \\
\hline
\end{tabular}

Table-2 shows that the largest group of participants (57\%) were in or had completed education to bachelor degree level and a further 19\% had completed post-graduate education. Less than $7 \%$ only had high school qualifications and $15 \%$ had a diploma educational level. These results reflect the fact that the majority had already completed their education and probably have used the internet before.

Table 3- Computer Knowledge of Respondents

\begin{tabular}{|l|l|l|l|l|l|}
\hline & Novice & Average & Above & Excellent & Total \\
& & & Average & & \\
\hline Frequency & 9 & 39 & 56 & 33 & 137 \\
\hline Percent & 6.6 & 28.5 & 40.9 & 24.1 & 100 \\
\hline
\end{tabular}

Table-3 shows that, in their own self-assessment, $65 \%$ of the participants have computer knowledge ranging from being above average to expert, and about $29 \%$ had some or average knowledge level. Less than 7\% considered themselves to be absolute beginners. The reason for asking this question was to have an indication of whether the population has the knowledge and vision to appreciate e-voting. 
Table 4- E-service use rate

\begin{tabular}{|l|l|l|l|l|l|}
\hline & Daily & Once a & 2-4 a month & Don't use & total \\
\hline Frequency & 118 & 13 & 2 & 4 & 137 \\
\hline percentage & 86.1 & 9.5 & 1.5 & 2.9 & 100 \\
\hline
\end{tabular}

Table 4 shows that $86 \%$ of participants use the internet and the e-services daily. This question was again asked to predict whether the population would be likely to know how to use an evoting system.

\section{Preferences towards voting methods}

The participants who have taken part in the Kuwaiti election system were asked to rate how confident they are in "the current Kuwaiti Election system based on how voting is managed and the votes counted". The reason for asking this question was to determine the confidence and satisfaction Kuwaiti voters have in the current paper-based voting system, covering both the way the election process is carried out and the way vote counting is managed. Figure 1 shows that just over half of the respondents have no confidence in the current election system in Kuwait. Only $14 \%$ of participants have confidence in the Kuwaiti Election process. This is a strong indication that a change in the voting system is needed to maintain confidence in the democratic process

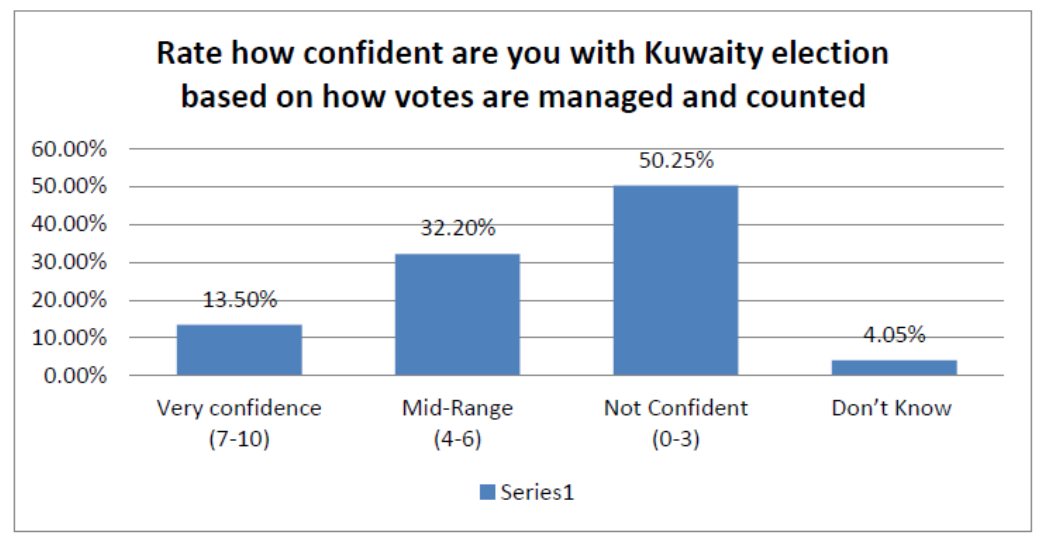

Figure-1 Confidence in the current election process in Kuwait

The next question was asked to find out from those people who are not satisfied with the current system, whether they would prefer to vote online rather than using the paper voting system. Figure 2 shows that the majority of the participants (64\%) indicated they would prefer using an evoting system rather than using the paper voting system. 
International Journal of Managing Information Technology (IJMIT) Vol.6, No.3, August 2014

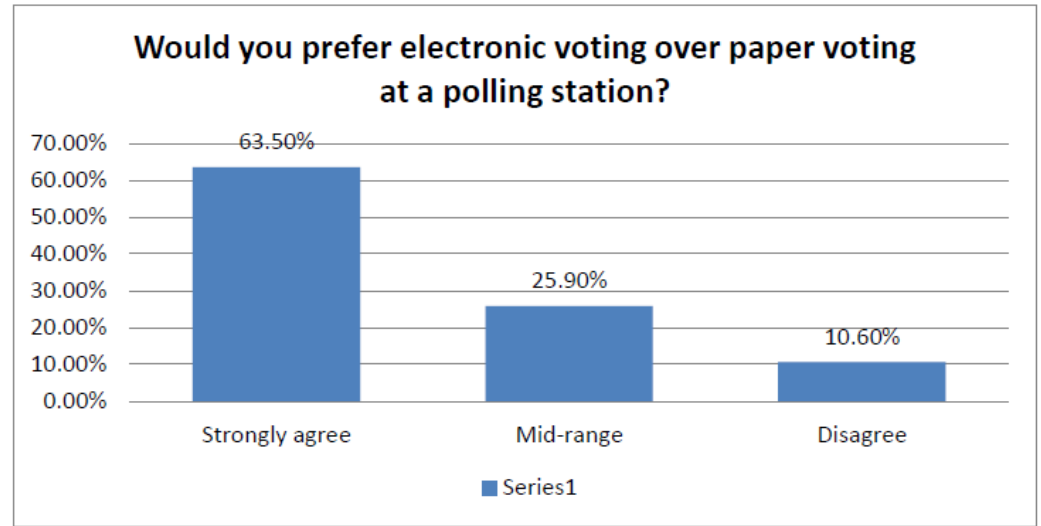

Figure-2 Preference of e-voting system at a polling station over paper voting

Figure 3 shows, however, that $59 \%$ of the participants would prefer e-voting to be conducted at the polling station rather than using internet voting (I-voting) in an uncontrolled computer environment. Figure 4 shows $60 \%$ of the participants indicated they would feel comfortable with the idea of electronic voting at a polling station.
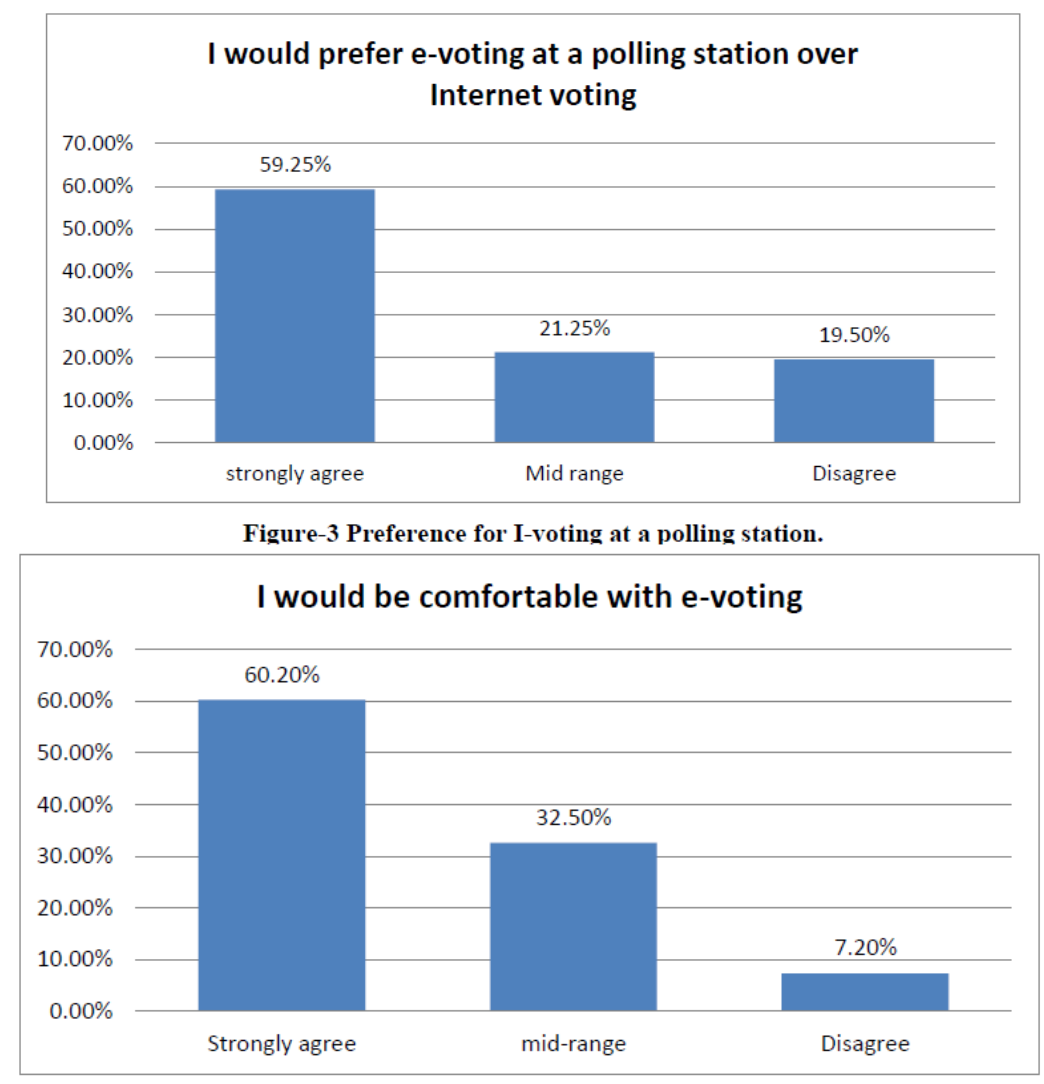

Figure-4 Comfortable with e-voting: 


\section{Reasons for preferring electronic voting at a polling station}

Over half (52\%) of participants strongly believed using e-voting at a polling station rather than using the internet at home would be more reliable as is shown in Figure 5.

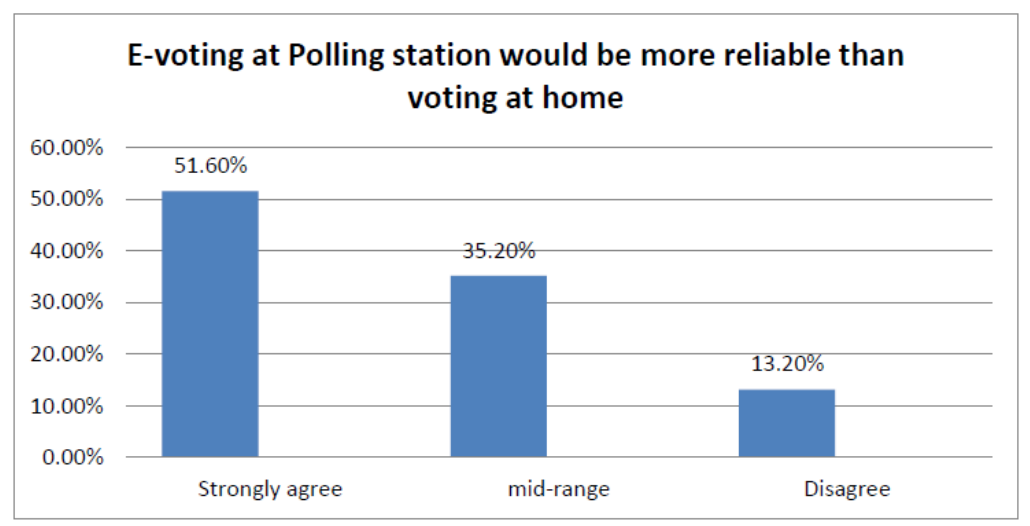

Figure-5 Belief in the reliability of e-voting at a polling station

One of the other potential advantages of voting at a polling station is that it could help to stop the illegal use of primaries. The illegal nature of these primaries means that all candidates remain on the ballot paper and the primaries rely on voters acting on the primary outcome. The primary elections are not subject to any official scrutiny so coercion and family pressures can affect the outcome. However, any improved anonymity in the voting system means a voter could break their commitment to the group and vote freely, ignoring the primary outcome, arguably rendering the primaries ineffective. When participant were asked if they agree that e-voting could help prevent primaries, Figure 6 shows $45 \%$ of respondents indicated they strongly agree, 34\% thought it might help prevent primaries, and $21 \%$ didn't think it would.

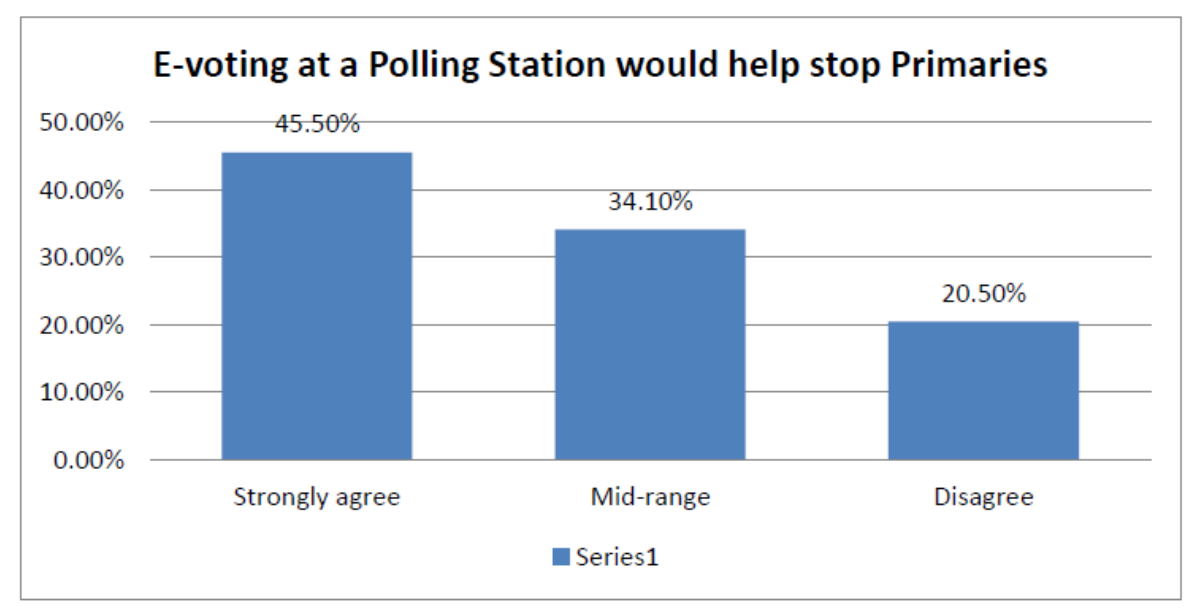

Figure-6 Belief in the effect on illegal primaries

Another potential benefit of voting at a polling station is that help can be available when needed. When participants were asked if voting at a polling station would give an advantage in providing help and assistance when problems arise, Figure 7 shows that $52 \%$ strongly support the idea. 


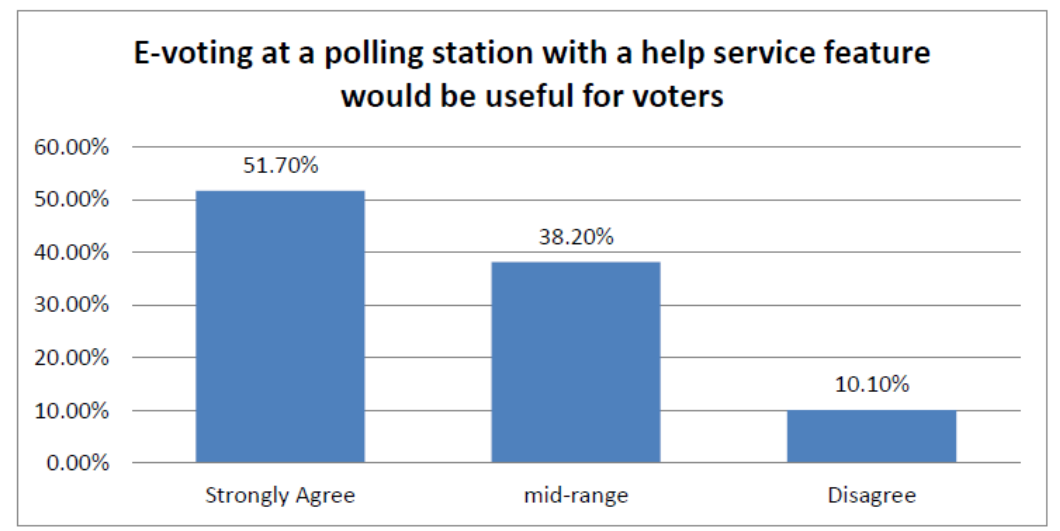

Figure-7 Belief that available help at polling stations would be an advantage

One of the advantages taken into account when considering e-voting at a polling station is whether this would help keep the vote counting process under strict control. When participants were asked if e-voting at the polling station would implement more control on the vote tallying process, just over $60 \%$ of the participants strongly agreed. Only $14 \%$ disagreed (see Figure 8).

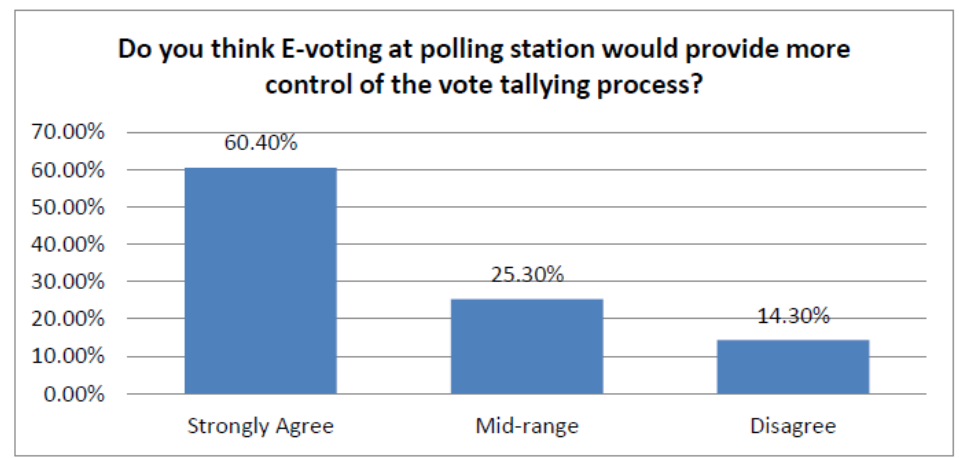

Figure-8, Belief that e-voting at a polling station will provide more control on the vote tallying

process

When participants who prefer using the e-voting were asked if using the e-voting system at a polling station would provide anonymity, just over half, 53\% were confident that an e-voting system would provide the necessary anonymity and privacy with only $11 \%$ disagreeing (see Figure 9). 
International Journal of Managing Information Technology (IJMIT) Vol.6, No.3, August 2014

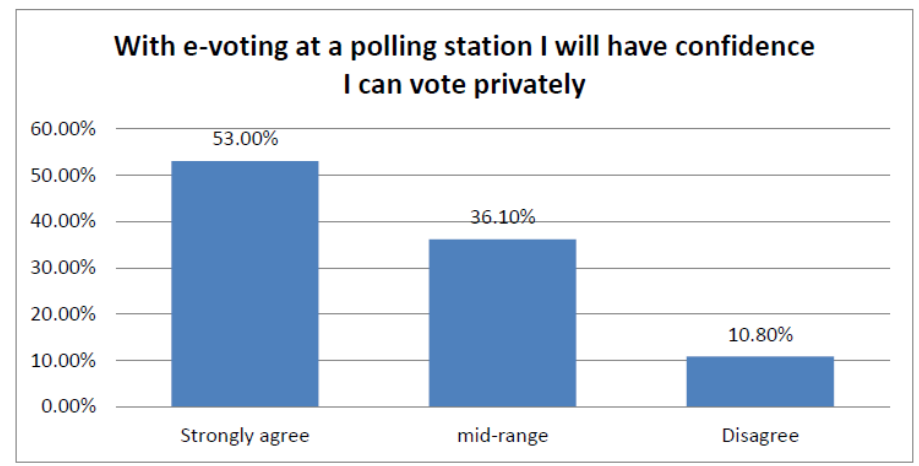

Figure-9 Confidence in e-voting at a polling station providing privacy

Electronic voting at a polling station is also likely to affect the incidence of coercion by family members. Figure-10 shows that $60 \%$ of participant who would prefer e-voting at the polling station thought that, when they use an e-voting system, nobody could influence their choice and they would be able to vote independently. Only $13 \%$ disagreed.

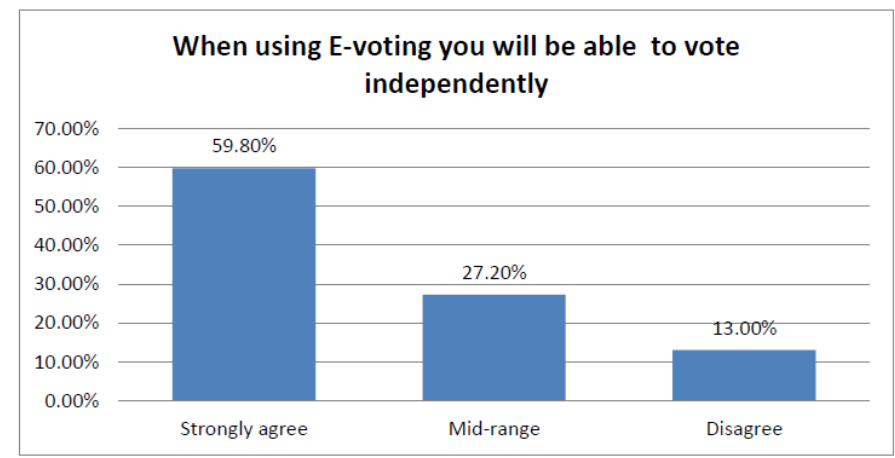

Figure-10 Confidence that e-voting can ensure independent voting

Figure 11 shows that $65 \%$ of the participant would like to consider the implementation of the evoting at a polling station as preliminary stage for implementing the full I-voting system in the future.

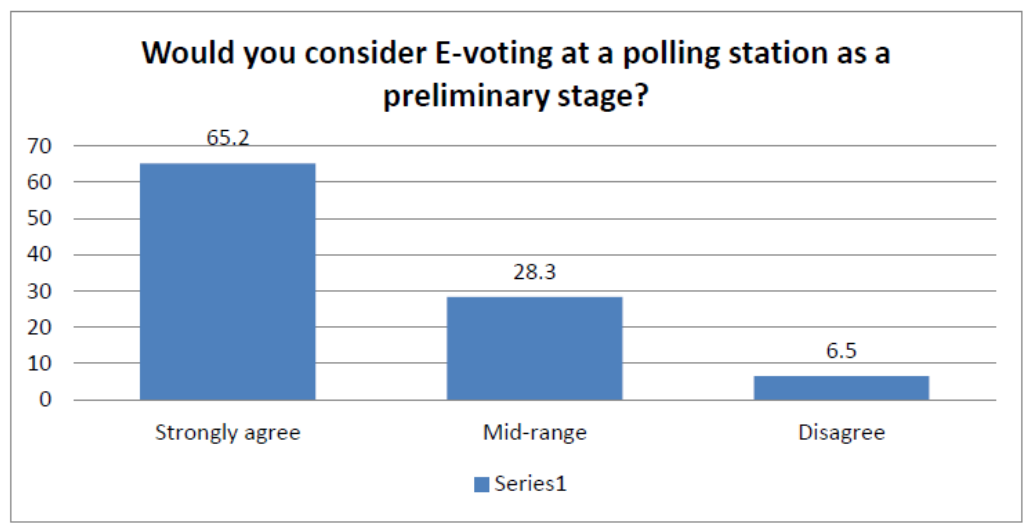

Figure-11 Considering E-voting at a polling station as preliminary stage 


\section{Additional e-voting features}

There may be addition features that could be added to an e-voting system in order to enhance the acceptance process of the e-voting system. Two features that the survey investigated are:

1. Confirmation of the candidate selection before the vote is recorded

2. The ability to verify votes through printed paper

Participants were asked if they thought either of these features would be desirable.

In general, over half the participants responded that these e-voting features were essential, especially the printed paper confirmation which nearly three quarters thought essential. Most of the remainder thought these features would be nice to have and only about $8 \%$ thought the features were unimportant. This result reflects the need for confirmation and verification through different channels to ensure the vote casting is correct. This gives an indication that, although most people thought an e-voting system would be acceptable, they would still require verification to ensure their votes are recorded correctly. (See Figures-11 and 12).

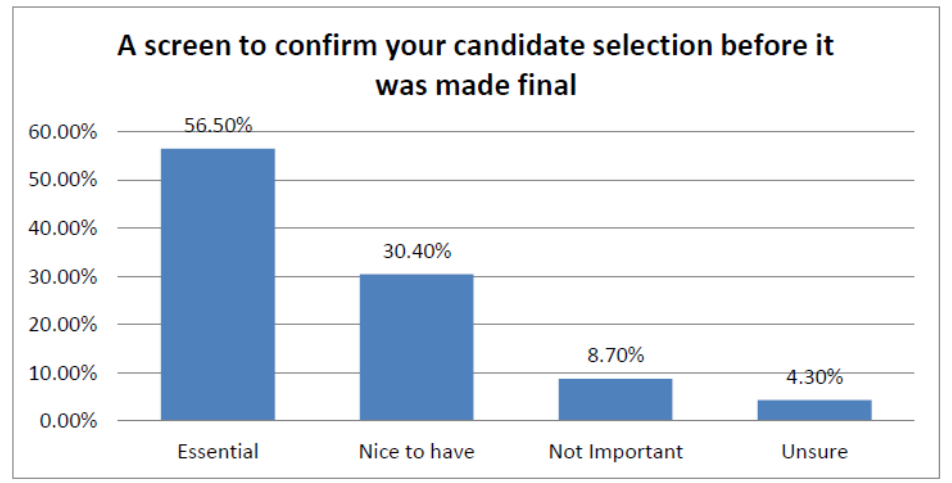

Figure-12 Confirmation of candidate selected before the vote is recorded

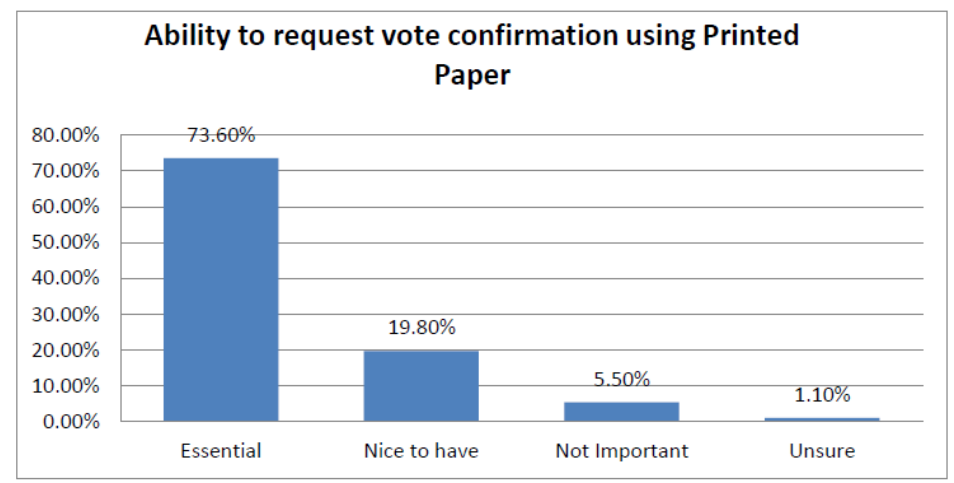

Figure-13 Ability to verify votes with a printed paper copy

\section{Survey results overview}

The survey result shows that more than half of the participants don't trust the way the current paper-based system is managed and not even the way the tallying process is done. A significant number of participants (64\%) said they would prefer to use e-voting over paper-based voting and most of them would prefer voting at a polling station because they think it is more reliable than 
voting via the internet at home. However, almost the same number of participants who prefer to use e-voting at the polling station also wanted to consider it as a preliminary stage for a complete I-voting project at a later stage.

It is also interesting to note the following:

- Figures 2 and 4 show slightly more of the participants said they would prefer e-voting than those who were comfortable to use it. This means that they are willing to use the e-voting system even if they don't know how to use it. This shows that they are willing to learn and take the necessary training in order to be able to use the e-voting system.

- The large majority of the participants (74\%) who wanted the feature of printed paper as a means for vote verification and to make sure that their vote is counted shows that while they are willing to move towards electronic voting, they are still not $100 \%$ in favor of a purely electronic system.

- In general, responses indicate a willingness to change the current paper-based voting system to an e-voting system at a polling station, but this is as far as their confidence in such a system would permit at this stage. Such a system could be seen as a preliminary stage or as trial experiment until the Kuwaiti people are ready to implement a full internet voting system.

\section{Summary of the Estonia I-voting system}

The survey suggests that a full internet voting system where users can vote at home would not be appropriate for Kuwait at this stage. Yet Internet voting has been implemented elsewhere, and in particular Estonia's experience of I-voting is well reported [11]

The Estonian e-voting system uses the internet voting as well as the traditional paper-based voting system. A voter has three options to cast their ballots:

1. Voting through the internet in an advance period before the election day.

2. Casting a paper ballot during the advance voting period, or

3. Voting on the election day with the paper ballot

Internet voting is only available for a certain period, usually from four to six days prior to advance voting days, and therefore not on election day. Electors are able to change their vote as many times as they like as long as the on-line polls are open and can still vote by paper ballot on election day, although this would disqualify their electronic ballot. The last voting cast is the only one that is counted, which replaces all the previously cast votes.

The main components of the Estonian e-voting system are a smart card reader, a voter application run on windows, MacOS or Linux operating system, and an Internet connection. When voting, the voter inserts their valid ID card into the card reader and opens the webpage for voting. After the voter is verified using the PIN1 of their ID-card, the voter is shown a candidate list appropriate to their electoral district and the voter can only make one choice. The voting system uses a "double envelope" schema [14] the vote is put into an inner envelope which itself is wrapped by an outer envelope that contains the digital signature of the voter. This process is designed to ensure voter privacy and security. Once the voter makes their voting decision, which is encrypted by the voting application, the voter confirms their choice with a digital signature (by entering the PIN2-code) and receives confirmation that the vote has been counted $[7,8]$. At the vote count the voter's digital signature (outer envelope) is removed and the anonymous encrypted vote (inner envelope) is placed in the ballot box. 


\section{Reasons for choosing the e-voting system at a polling station}

It can be seen that there are some similarities between Estonia and Kuwait, such as:

- both are small countries in size and population

- both have ID cards for all citizens

- most of the people have access to the internet

These similarities give an indication that Kuwait could adopt the Estonian I-voting system rather than create their own. However, Kuwait has different social issues to those of Estonia. These different issues do not support the use of the same system as was used in Estonia, these issues are: - tribal families

- family-oriented culture

These two issues could have a significant effect on the Estonian I-voting system if it was to be implemented in Kuwait society. Tribal families often hold primaries in order to coordinate their votes (against the Kuwaiti Law) so that they can win a seat in the parliament [1] Also Kuwait is a family-oriented country where family values are very high and sometimes this might affect a family member's decision, for example, one family member can sometimes decide or influence the voting choice of other family members.

I-voting is an unsupervised election system, which means voters are using their own computers to cast their vote. This could be the weakest link in I-voting as there is no guarantee of the voter's machine being secured. Although the Estonia case shows this need not be a fundamental obstacle to making I-voting secure, it certainly introduces more complexity and this will not make the population have confidence in the system. The survey shows this could be a major obstacle for Kuwait as, although most voters favor e-voting, confidence is not strong with, usually, less than two thirds who could appreciate of the benefits.

Therefore, because of the Kuwaiti social issues, the risk of using an internet voting system in an uncontrolled environment, and the result of the survey conducted, we suggest a new proposed system that takes these issues into account, advocating e-voting at a polling station, which is in a controlled environment, rather than using the I-voting system as the next stage of development of the Kuwaiti voting system.

\section{A proposed e-voting system for Kuwait}

Trust is a very critical issue in any automated system, if users don't trust the system due to some problems, then the system will fail. This also applies to any voting system, voters will only have confidence in the voting system if they use it and the system produces the right results in return. As the literature says $[12,17]$ you cannot develop the desired system without correct and complete requirement analysis within the system design process.

Based on the survey result, a little bit more than half of participants have no confidence in the current paper system used in Kuwait and only 14\% have confidence in it (figure-4). Also, when participants were asked if they would an electronic system instead of the current paper-based system, $64 \%$ voted in favor and only $11 \%$ voted against (figure-5), with the same percentage of people who wanted to change to an electronic system also saying they would feel comfortable 
with e-voting system (figure-1). All these results show that there is willingness to change the current system to an electronic system.

Therefore, we have suggested introducing a new e-voting system which can meet the Kuwaiti population's requirements. The new system proposed is an e-voting system at a polling station with the use of a paper trail feature combined with some features and procedures of the paper based system that has been used for many years in Kuwait. The purpose of this combination is twofold, one is to enhance the confidence and trust of the new system by giving voters the ability to check that their printed copy matches their electronic vote before inserting the paper into the ballot box, and the other is to use the paper copies for a manual recount if any candidate files a complaint over the vote counting. In addition, people will also find the system easy to deal with because most of the old paper-based system procedures and principles will exist in the new system.

Although e-voting may seem the perfect application for technology, in reality, it is difficult to achieve [6]. In any electronic voting system, security and reliability are important attributes [16]. The steps to achieve this reliable and secure proposed e-voting system for Kuwaiti elections are as follows:

\subsection{Definition of Election Districts}

This process already exists and is carried out by the government officials before the election campaign, to define the district boundaries and the number of candidates to represent each district.

\subsection{Determining the Voters}

This process also already exists and is also carried out by the government to determine all the eligible voters for the state of Kuwait. In general, all adult persons at the age of 21 years and above have the right/obligation to participate. Police and military employees are eliminated from voting by the Kuwaiti state law.

\subsection{Setting-up Election Centers}

This process is performed after elections districts have been defined and before the voting time period is announced. Its goal is to provide the infrastructure, which allows for the election process. During this process the authorized election centre staff, along with individuals authorized to supervise the election process for each election centre, are identified. This process, again, already exists, but the staff authrised to supervise the centre will need additional training to cover the electronic systems provided.

\subsection{Setting-up the polling stations}

The aim of this process is to setup the polling stations for each district. Each polling station should be equipped with many e-voting touch screen machines, based on the room size and number of voters in the district. These e-voting machines should employ a card swipe system for use with the voter's ID card. 


\subsection{Identification and authentication of the voter}

On the election day, to ensure that the voter votes him or herself, the voter should show their identification card to the officials in order to enter the polling station. The officials would check and verify the picture and district of the voter before directing them to an available e-voting machine.

\subsection{Verifying the voter electronically before they cast their vote}

To avoid coercion, no-one, not even authorities, should be able to extract the value of the vote [5] Going to the polling booth alone to use the voting machine to cast their vote, enables the voter to cast their vote freely and anonymously without any coercion.

At the polling booth the voter must swipe their digital ID card to give a second, electronic identification of the voter's name, district and eligibility to vote, matched to the government registration list. The screen will then show the candidate list for that district only.

\subsection{Casting the vote}

Once the voter chooses their candidates, they must submit their votes with a press of a button which takes them to another screen which shows confirmation of the chosen candidates. The voter then has to choose one of the two options, either to confirm the selection and exit the system, or to modify their choices by going back to the previous screen to modify their selection. This confirmation process is proposed to comply with survey result that shows $57 \%$ of participant said it is essential and 30\% said it is nice to have a screen to confirm their candidate selection before it was made final (figure-10).

Votes are then stored in the system. Once the voter confirms their selection, a paper ballot is printed to confirm their voting selection. The voter has to take the paper ballot, check his/her selected candidates and then insert it in the ballot-glass box in front of the adjudicator as in the traditional paper voting system. The printed paper is also added as feature to comply with survey result that shows $74 \%$ of participants said it is essential and $20 \%$ said it is nice to have a system with the ability to request vote confirmation such as a printed paper (figure-11). These two features should enhance the user trust and confidence of the system. In order to comply with the system requirements of democracy, the system must ensure the voter has to vote only once, and the paper ballot is only printed if the voting process is done.

Uncoercibility and prevention of vote buying and extortion can be improved by the proposed evoting system but it also requires the help of the government officials to ensure that no one takes the original printed paper or a copy of it outside the polling station. As some people argue, coercion cannot be totally prevented by technology alone [9].

\subsection{Tallying the votes}

This process is performed to validate votes and determine the number of votes each candidate has received, along with any canceled votes. This process should take place at the end of the election day, in every main polling station, and finishes when all votes have been directly validated and tallied electronically by e-voting machines. In the first elections using this system it will also be 
necessary to count the votes manually by the election officials using the paper copies. Although this will be time consuming, it will build confidence in the electronic system so that in later elections the votes can be counted by only the electronic system, with the paper votes being counted only if the losing candidates challenge the result.

In the case of the e-voting machine, the voting information could clearly be transported to the central location more quickly and more reliably using an electronic network. However, confidence in the system must be maintained, so in the first elections using the system, once voting has closed, the officials should transport the vote storage devices from each machine to centralized locations for vote counting, much like they would do with paper-based systems. The electronic votes transmitted via the network would not be officially recognized until verified by tabulating the results which are stored on the storage devices from the e-voting machines

The paper copies of votes can be handled in the traditional way, with all boxes brought to the main polling station, the boxes are opened under the supervision of the election officials and the candidates'

representatives to validate each vote. Valid votes from all parts of the same district are then added together. At the end of this process the results of the network transmission of votes and the manually transported electronic votes can be compared to the result of the paper votes for verification purposes. If the results are the same, the supervisor of the main polling station can announce the result to the public through the available media. The electronic vote storing devices and the paper copies of votes should then be kept safe for as long as the state law designates.

If there is no match between the electronic results and the paper results then the result of paper system should be approved as this is similar to the existing, traditional voting system. Experts would need to review the e-voting system under the supervision of the election officials to determine the causes of any discrepancy.

\subsection{Recounting the votes}

The fact that there is already more than one method of counting should reduce the number of recounts requested. However, the fact that the physical paper copies exist ensures that a recount can be made as many times as desired.

\section{Other functional requirements of the e-voting system}

An e-voting system would be considered acceptable if it is capable of providing the right results for the election process in an efficient way, and allowed voters to feel confident in the reported data. Clearly the data must be correct as there is generally a tight correspondence between the data requirements and particular functions of the solution system [3].

The e-voting machine needs data on which voters are eligible, the district they belong to, the candidates and the number of candidates a voter can select. Once voting has started the voting machine needs to know which voters have already voted to ensure no-one can vote twice. This requires the voter ID card details to be able to check the voter's identity. The system should be able to log all activity, but not the detail of how any particular person has voted. 
International Journal of Managing Information Technology (IJMIT) Vol.6, No.3, August 2014

Casting the vote has to be simple and straightforward. The e-voting machine and the software installed should allow the voters to cast their votes quickly and conveniently without any special skills. No computer knowledge should be necessary to cast a vote.

The system should not allow any tallying process until the end of election period. After the election period has finished, the voting system has to be isolated from any external access. Election information should not be known to anyone until after votes has been consolidated and tallied.

\section{Building confidence in e-voting in Kuwait}

This section discusses and compares the proposed Kuwaiti and Estonian systems. There are some similarities between the Kuwaiti suggested e-voting system and the Estonia system. For instance, both systems use the e-voting system within the polling station, however, the proposal for Kuwaiti is a more cautious, evolving system that can move towards the full I-voting system used in Estonia in stages, building confidence in the system as it evolves.

The different aspects of confidence building used to build confidence in the proposed Kuwaiti system are as follows:

\subsection{Familiarity}

In introducing an electronic voting system to the Kuwaiti environment for the first time some of the features from the current paper system in Kuwait have been used, for example the printing of paper copies of electronic votes and then posting these copies in a ballot box so they can be counted. Choosing these features from the paper system in the suggested system does not mean they are better or more reliable than the features used in the Estonian system, but are incorporated only to make the suggested e-voting system easier to use and more familiar to the Kuwaiti citizens. Gradually, the features taken from the paper system that are not needed will be changed and disappear as more people become used to and trust the new e-voting system which eventually would be similar to the system used in Estonia.

\subsection{Identification Methods}

Both countries have ID cards as a compulsory issue and these can then be an important identification method for an e-voting system. Strong cryptographic solutions based on digital signatures and a public key infrastructure are used in Estonia. While this could also be used in Kuwait, the suggested voting system also employs a manual check of the ID card against the government list before the voter enters the polling station which is then checked again by the evoting machine before the vote is cast. Both countries use the card reader in order for the system to identify and verify the voters as such card readers are already commonly used. The duplication of the identification in the suggested Kuwaiti system would be used to build confidence in the cryptographic methods. It will also correspond more closely to the paper system and therefore be more familiar to voters. Once Kuwait voters become used to the e-voting system and learn to trust the cryptographic solution, the manual checking could be dropped. 


\subsection{Vote Separation from Voter Identification}

The Estonian approach uses the digital signature to check if the voter is eligible to vote, and if so, the vote (inner envelope) is counted, and separated from the signature of the voter. In this case the votes will be kept separate from voter identification. Since the system allows for vote cancellation, the Estonian approach could be questioned as the voter gets no proof of the voter identity separation from the vote. This relies on trust that the government and National Election Committee (NEC) would do this process fairly. The survey shows that Kuwaitis are not yet ready to trust a system to this extent, and so a paper trail has been incorporated into the system. All votes cast are printed for auditing purpose and to inform the voters that their votes were registered and cast successfully. Once the voters have seen that the electronic systems can produce results that are equivalent to the paper system the voters will gain confidence in the sophisticated electronic security measures, enabling the paper trail to be dropped.

\subsection{Restricting Votes to a Polling Station}

The Estonian e-voting system is more open to possible threats, such as from web site spoofing and malware which could lead to re-direction to a site other than the one apparently displayed on the screen [10]. Whereas, in the suggested Kuwaiti system, an e-voting machine is used with a pre-designed application that does not use a web browser which makes it more secure than Ivoting.

\subsection{Technical Support}

In the Kuwaiti suggested system case a small team of technical people would need to be available in each polling station in case of hardware malfunctions or software problems. Such a service would not be available for voters using the Internet from private computers in Estonia.

\subsection{Usability}

Both the Estonian and proposed Kuwaiti systems use a Smart card reader because it is easy for people in both countries to use since people are familiar with using it in other government processes. Estonian voters can use any operating system or Internet browser to cast their vote but the need to install hardware and software to perform the voting task makes it less usable. However, the software has the compatibility with tools and technologies that can help disabled voters. In the Kuwaiti suggested system, there is no additional hardware or software required to cast the vote as I-voting would not be included, at least in the first instance. The voting process could be made straightforward and is easy to use when using the e-voting machine.

Training to show the voters how the system works would overcome this problem in time, indicating that the government could introduce I-voting gradually until technology can come-up with a better solution [2].

\subsection{Vote Collation}

At the end of the voting period, the voting data will be transported to the main polling station for counting all votes for that district. The election officials for each polling station within the same district will transport the media storage to the central location, but also the data could be sent over the network (i.e., the internet). If both are introduced at the same time the transported version could be used to test and build confidence in the internet transmission. This would help build confidence in the internet for full internet use with a browser. 


\subsection{Government Support}

In the Estonian election, no security incidents have been reported. However, this is not evidence that none has occurred. The deployment has been generally accepted by citizen, politicians, and election officials $[7,8]$. This could be due to the fact that it was supported by the government of Estonia. For the Kuwaiti suggested system, government support and participation is also very important to build confidence.

\subsection{Pilots}

It is intended to first implement the suggested system in a pilot experiment to test its quality. Each new feature will be tried and tested in one area before wider roll-out to the whole country, as is explained in the next section.

\section{Future Work}

The survey shows the majority of the participants $(65 \%)$ who prefer e-voting at a polling station, think it is good idea to consider the voting at the polling station as a preliminary stage for implementing the full I-voting system in the future (figure-11).

A pilot trial can be suggested for future work or implementation to the proposed e-voting system with a number of suggested steps to introduce the e-voting and I-voting systems to a population that is not yet ready for it.

Thus, the suggested steps are as follows:

1. The e-voting system at a polling station is tried in a single district. Manual identification on entry to the polling station would be used as well as electronic identification with the Swipe reader at the polling booth. A paper version of each vote should be printed and put in a ballot box and then both the paper and electronic votes could be counted to see if they match. The electronic votes would also be transported to the central location by two means, the Internet, and a physical transportation of the vote storing media. Again the results from the two methods would be compared to check that they match.

2. On the next parliament election, the e-voting system is again tried, but this time in more areas and this time only the electronic version is counted unless the vote is challenged by one of the candidates, in which case the paper vote is used for the recount. The two transportation methods should be continued at this stage to demonstrate the Internet can be trusted when appropriate security software is used. The manual identification of voters at the polling station should continue.

3. The e-voting system should then be used throughout the country. Manual identification of voters should continue until all areas had used the double checking system proposed at least once. 4. Once the trust of the e-voting system has been gained, it may be possible to drop the printing of the votes when people realize the electronic count is just as reliable as the paper count. This would be a big step forward as it would make the system much faster to process and more reliable if it does not depend on printer equipment. Similarly, the manual checking of voter identity could be dropped in favor of the cryptographic identification methods.

5. Also, once the trust had been gained in e-voting, an internet voting system could be trialed in one area. If the user interface on the Internet system is similar to that on the voting machine it will 
be better trusted by the people. When the I-voting system is implemented, the strongest cryptographic methods based on digital signatures and a public key infrastructure should be used, similar to the system used in Estonia. Also more security features should be enforced in order to prevent hacking or virus attacks.

6. If the Internet voting system is successful it could be rolled out to the whole country.

At each stage, surveys should be conducted after each election to determine if the Kuwaiti people are happy that the electronic voting system is working adequately before moving to the next stage. The surveys should also check to see if coercion and illegal primary elections are still a problem, to see if the e-voting system is succeeding in improving the democratic process, and to check to see if the voters are more satisfied and confident in the new system than they were for the current voting system.

\section{Conclusions}

In this paper, we first gave an overview of the paper ballot system that has been used for many years in the state of Kuwait. Then we identified some of the drawbacks of the current voting system which the new suggested system should resolve.

When proposing a new e-voting system, it is necessary to perform the election in a secure manner. For Kuwaiti people to trust the e-voting system, it has to be secure, reliable and satisfy all voting requirements of a modern democracy. Thus, we have identified the e-voting principles and secure steps that should be followed when implementing the e-voting system in Kuwaiti with emphasis on the social issues that can have an effect on the Kuwaiti election environment. A survey was conducted to check the acceptance of e-voting for parliament elections and to replace the paper voting system currently used in Kuwait. The result shows the following:

- The majority of participants have little trust on the current paper voting system.

- Most of the participants would like to change to an e-voting system

- Most of the participants would prefer to vote at polling station rather than at home as they believe it would be more secure

- Most of the participants would like to have the chance to confirm their vote electronically and also have a printed paper confirmation which can be counted.

From the survey it was found that although there was a willingness to move to a more electronic system, a lack of confidence would be a major issue if an internet voting system was introduced. This paper has therefore suggested a new e-voting system that incorporates many features and principles of the old paper system to help the Kuwaiti citizens to accept the new system and feel acquainted with it.

An analysis of the voting system in Estonia was carried out to see if this working system would be suitable for Kuwait. However, it was concluded, based on the result of the survey, that a more cautious, step by step move towards full internet voting would be necessary to build confidence in the system by the Kuwaiti people. E-voting at a polling station provides an intermediate stage to employ electronic voting without moving completely to internet voting. Such a system would build confidence in the technology to allow internet voting at a later stage.

For future work, a series of pilot experiments should be implemented for each stage of the development of e-voting and internet voting systems until a system similar to the Estonian system is eventually developed. At each stage there would have to be an emphasis on the most basic 
principles of an electoral process, such as correctness, anonymity, secrecy, and freedom from coercion. It will be an important part as a future project to explain, reason, and test the implementation of the new e-voting and internet voting systems against those principles.

\section{References}

[1] Abubakar A.I, (2013) Nahaj dulls primary power, http://www.arabtimesonline.com/NewsDetails/tabid/96/smid/414/ArticleID/177978/reftab/96/t/Nahajdulls-primary-power/Default.aspx, (viewed: 20 Jan 2013).

[2] Alhammar, J. (2011) Towards internet voting in the state of Qatar, PhD Thesis, Loughbrough University, UK

[3] Bray, I. (2002). An introduction to Requirement Engineering, Addison Wesley, Harlow Essex, UK.

[4] Brown, N.J. (2008). What is at Stake in Kuwait's Parliamentary Election, Carnegie Endowment, Web Commentary, Middle East program, May 7, 2008.

[5] Burmester, M. \& Magkos, E. (2003) "Towards secure and practical e-election in the new era", Advances in Information Security - Secure Electronic Voting, Kluwer Academic Publishers, 2003. pp 63-76.

[6] Daimi, K., Snyder, K. and James. R. (2006), "Requirement Engineering for E-voting systems", In Proc of the Int. Conf. on Software Engineering Research and Practice, SERP 2006, Las Vegas, Nevada, USA, June 26-29, 2006, Volume 1. CSREA Press 2006, ISBN 1-932415-90-4

[7] Estonian National Electoral Committee (2007a) Main statistics of E-voting, http://www.vvk.ee/english/IvotingComparison2005,2007.pdf (viewed 05 May 2011)

[8] Estonian National Electoral Committee (2007b) Parliamentary elections 2007: statistics of e-voting, http://www.vvk.ee/english/Ivotingstateng.pdf (viewed 05 May 2011).

[9] Gritzalis, L. Katsikas, S. (2002) "Revisiting legal and regulatory requirements for secure e-voting", In Proc. of the 16th IFIP International Information Security Conference (IFIP/SEC-2002). Egypt, 6-8 May 2002.

[10] Jefferson. D., Rubin. A., Simons. B., Wagner, D. (2004) A Security analysis of the secure registration and voting experiment, http://servesecurityreport.org (viewed 05 July 2010).

[11] Maaten, E. (2004) "Towards Remote E-Voting: Estonian Case.", In Proc. of Electronic Voting in Europe - Technology, Law, Politics and Society: Workshop of the ESF TED Program Together With GI and OCG, July 2004, Vol 47, pp. 83-90, Schloß Hofen / Bregenz, Austria, Prosser, A. and Krimmer R. (Eds.).

[12] Peters, J. and Pedrycs, W. (2000) Software Engineering - An Engineering Approach, Wiley, New York

[13] Phillips,D., Von Spakovsky H. (2001) "Gauging the risk of Internet elections." Communication of the ACM, vol.44, no.1, pp. 73-85.

[14] Skagestein, G., Haug, A.V., Nødtvedt, E., Rossebø, J. (2006) "How to create trust in electronic voting over an untrusted platform", In Proc. Electronic Voting, August 2-4, 2006, Castle Hofen, Bregenz, Austria, 107-116

[15] Slovak, M., Pettai, V. (2008) "The parliamentary election in Estonia, March 2007", Notes on Recent Election/Electoral Studies, vol.27,no.3,pp, 547 - 577.

[16] Spycher,O., Volkamer, M., Koenig, R. (2011) Transparency and Technical Measures to Establish Trust in Norwegian Internet Voting, VoteID'11, In Proc. of 3rd International Conference on E-Voting and Identity, Tallin, Estonia.

[17] Summerville, I. and Sawyer, P. (1997) Requirements Engineering- A good Practice Guide, Wiley,Chichester, Essex, UK.

[18] Toumi, H. Bureau Chief, (2012) "Rewards to boost anti-vote buying drive in Kuwait", Gulfnews.com, Nov 262012.

[19] VotingNews (2011). Don't push panic button on e-vote, Edmonton Journal, Dec 14, 2011, http://thevotingnews.com/dont-push-panic-button-on-e-vote-edmonton-journal/, (viewed 20 Jan 2013 